\title{
Environmental performance assessment of Napier grass for bioenergy production
}

Nimmanterdwong, Prathana ; Chalermsinsuwan, Benjapon; Østergård, Hanne; Piumsomboon, Pornpote

Published in:

Journal of Cleaner Production

Link to article, DOI:

10.1016/j.jclepro.2017.07.126

Publication date:

2017

Document Version

Peer reviewed version

Link back to DTU Orbit

Citation (APA):

Nimmanterdwong, P., Chalermsinsuwan, B., Østergård, H., \& Piumsomboon, P. (2017). Environmental performance assessment of Napier grass for bioenergy production. Journal of Cleaner Production, 165, 645655. https://doi.org/10.1016/j.jclepro.2017.07.126

\section{General rights}

Copyright and moral rights for the publications made accessible in the public portal are retained by the authors and/or other copyright owners and it is a condition of accessing publications that users recognise and abide by the legal requirements associated with these rights.

- Users may download and print one copy of any publication from the public portal for the purpose of private study or research.

- You may not further distribute the material or use it for any profit-making activity or commercial gain

- You may freely distribute the URL identifying the publication in the public portal 


\title{
Environmental Performance Assessment of Napier Grass for Bioenergy Production
}

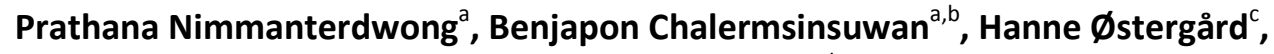 Pornpote Piumsomboon ${ }^{\mathrm{a}, \mathrm{b}, *}$}

\author{
${ }^{a}$ Fuels Research Center, Department of Chemical Technology, Faculty of Science, Chulalongkorn University, \\ 254 Phayathai Road, Pathumwan, Bangkok 10330, Thailand \\ ${ }^{b}$ Center of Excellence on Petrochemical and Materials Technology, Chulalongkorn University, \\ 254 Phayathai Road, Pathumwan, Bangkok 10330, Thailand \\ ${ }^{c}$ Department of Chemical and Biochemical Engineering, Technical University of Denmark, DTU, \\ Søltofts Plads 229, 2800 Kgs. Lyngby, Denmark
}

\begin{abstract}
The industrial production of chemicals and energy carriers has grown enormously with the support of new technologies. A proper assessment is needed to provide broader aspects for long-term sustainability. The purpose of this study was to evaluate the environmental sustainability of a biorefinery based on lignocellulosic biomass feedstock using emergy analysis and to propose the method to minimize material consumption and waste. The concept of emergy is to express the record of all resources used by the biosphere in earlier steps to produce a product or service, in term of solar energy equivalence. This idea provides the quantitative indicators involving the resource use and the percent renewability of the systems. For the proposed biorefinery model, Napier grass (Pennisetum purpureum) grown in Thailand was used as lignocellulosic feedstock. An emergy assessment was performed in two parts, comprised of the evaluation of the feedstock cultivation and of a biorefinery producing liquid fuels, methanol, steam, electricity and other by products, i.e., high purity $\mathrm{CO}_{2}$, sulfur. The emergy results revealed that the bio-based products depend mostly on non-renewable resources used in both biomass cultivation and biorefinery stages. For Napier grass cultivation, most of the emergy support came from local resources in term of evapotranspiration of Napier grass (33\%) and the diesel consumption during the cultivation process (21\%). The emergy sustainability indicator of the cultivation was 0.81 . The emergy sustainability indicator of the whole process from cultivation to biorefinery stages dropped to 0.25 , since the biorefinery section required solely economic inputs of which most were non-renewable. In conclusion, the implementation of the integrated biorefinery concept could minimize material consumption and waste generation and it also has higher performance in terms of the emergy compared to other existing processes.
\end{abstract}

Keywords: Emergy assessment, Biorefinery, Napier grass, methanol, combined heat and power

*Corresponding author telephone:+6622187676; e-mail: pornpote.p@chula.ac.th 


\section{Introduction}

The recent development of biomass utilization systems to reduce the dependence on fossil fuels has been encouraged to provide effective strategies to achieve a solution to both the economic and environmental aspects of utilizing non-renewable fossil fuels. Therefore, the ideal biofuels must be drawn from the feedstock that provides lower greenhouse gas emission than conventional fossil fuels through their life cycle with less impact on food security.

Using biomass as a feedstock in a biorefinery to convert the biological materials into fuels and chemicals is still in a nascent state. Industries can either directly use food crops as feedstock or replace existing arable land for food crops with energy crops which would cause higher food prices and triggers the farmers to clearing more forest to grow more food crops (Tilman, Socolow et al. 2009). However, using the biomass from energy crops as feedstocks for a biorefinery requires large area of land to provide sufficient supply. Alternatively, biomass residues, such as straw, husk and other agricultural co-products or wastes are the type of promising feedstock for advanced biofuels. Another alternative could be those perennial warmseason grasses, such as Napier grass (Pennisetum purpureum), Miscanthus (Morandi, Perrin et al. 2016), Indiangrass and switchgrass (Felix and Tilley 2009). These crops could produce reasonable yields even under severe conditions on marginal or degraded lands abandoned from agricultural usage with low maintenance (Campbell, Lobell et al. 2008). Napier grass, which has been widely used to feed local cattle in Thailand and recently promoted as a bioenergy crop by the Thai government, is studied here as an example of a lignocellulosic bioenergy feedstock.

An important concern for utilizing biomass as a substitution for primary fuel is that biomass production at present indirectly involves consumption of non-renewable resources (Giampietro, Ulgiati et al. 1997). The question arises whether the present bio-based technologies can potentially replace the existing fossil-based processes in both economic and environmental aspects. Thus, a number of assumptions however have been made and systematic quantitative information is required to use as a guideline for decision making.

Over the past decades, several tools and methods have been proposed to provide comprehensive criteria guidance for decision-making, such as techno-economic (Swanson, Platon et al. 2010), life cycle analysis (Owens 1997), exergy (Dincer and Rosen 2012) and emergy analyses (Odum 1996). The techno-economic studies provide the economic feasibility aspect whether the production process gives benefits in the range of the given time. By using feasibility analysis, Fontoura (Fontoura, Brandão et al. 2015) found that converting an Elephant grass into a biorefinery adds value is economically feasible. However, the value of the present products is temporary and inverse to real wealth. Thus, the economic benefit does not reflect long term sustainability. The life cycle analysis (LCA) is a method defined to analyze the environmental impacts of the production system by focusing on emission throughout the life cycle of the analyzed product. By using LCA, Chang (Chang, Lin et al. 2017) compared two bioethanol production schemes (using Napier grass and short rotated Eucalyptus as feedstocks) and the analysis could identify the process that provided lower environmental impact. Thus, the LCA could provide the guidance for process improvement in the aspect of environment. However, the LCA analysis does not take the aspect of economics into consideration. 
In the current study, emergy analysis was employed to indicate the sustainability of the proposed bio-based system. The analysis considers both economic and environmental factors by analyzing all the inputs, both natural and man-made resources, used to develop a product. The concept of emergy was originally formulated by H. T. Odum as the amount of available energy of one type (usually solar) that is directly or indirectly required to produce a product or service (Odum 1996). It includes the amount of free natural inputs (solar, wind, rain, geothermal, etc.) and economic inputs (materials, man-made energy, and labors) to the system and is expressed in units of solar equivalent joule (sej).

In our previous literature, the feasibility of two agricultural crops, oil palm and Jatropha, as bioenergy feedstocks in Thailand was previously evaluated to identify suitable species for energy sources (Nimmanterdwong, Chalermsinsuwan et al. 2015). By using emergy accounting, it was found that oil palm required less emergy input per unit biomass and had a higher renewability than Jatropha, i.e., oil palm was the preferable choice for a biorefinery. Moreover, by using emergy analysis, we could point out that large portion of human labor required for harvesting and transporting in the biomass cultivation stage. Neglecting this portion of energy may probably cause a misleading conclusion. The study on cultivating Miscanthus as energy crop reveals that different logistic strategies affect the emergy used or the environmental cost of the entire process (Morandi, Perrin et al. 2016).

In recent years, the idea of biorefineries has become promising alternative strategies for industrial development. To achieve the energy demand and climate change mitigation goals, the idea of extracting energy from biological materials has been promoted. The facility that converts those materials into fuels, energy, chemicals and materials is what we called biorefinery (Sengupta and Pike 2012). A variety of different inputsfeedstocks and conversion technologies can be employed in biorefineries system. The recent emergy study was done on the bioethanol production in Siena, Italy. It was found that using local resources (straw and residual geothermal heat) to produce bioethanol provided an appropriate solution for fossil fuels substitution (Patrizi, Pulselli et al. 2015). Nevertheless, by using emergy assessment, it was also found that the biorefineries do not completely use renewable resources. Most bioenergy such as bioethanol (Pereira and Ortega 2010) and biodiesel (Cavalett and Ortega 2010) production processes still require supplemental non-renewable resources. Our purpose of this study was to evaluate the environmental sustainability of a biorefinery based on Napier grass as a lignocellulosic biomass feedstock and to minimize material consumption and waste.

\section{Methodology}

To achieve sustainable bio-based industries, the biorefinery case studies were designed using Aspen Plus software to simulate an industrial symbiosis with the closed loop concept of materials and energy through reuse and recycling. The materials and energy in the process become more optimally used, and the waste generation is minimized. The system boundary were included the feedstock cultivation, where the data were obtained from the literature and published surveys in Thailand, and eight production processes of the biorefinery (Fig. 1) in total of nine processes: (1) cultivation and transportation of Napier grass, (2) gasification, 
(3) combined heat and power plant (CHP), (4) syngas cleaning, (5) fuel synthesis, (6) hydroprocessing (HDP), (7) methanol synthesis process, (8) carbon dioxide capture and (9) waste water treatment.

\subsection{Crop production}

Napier grass cultivation data was collected and reported by researchers from Pakchong, Nakhon Ratchasima province in northeastern of Thailand in year 2013 (DEDE,2013). Napier grass can be harvested 56 times per year. The first harvest takes place four months after planting and ratoons are harvested every other month for up to seven years. To maintain the crop yield during the 7 years, soil amendments and harrowing are required after every harvest and weeding are performed twice a year. Other general assumptions were as follows: (1) local renewable resource information was based on Thailand data including solar radiation, rain and geothermal which were taken from the Thai Meteorological Department (2016); (2) evapotranspiration of Napier grass was evaluated using the FAO procedure and the Napier crop coefficient data from Thai Royal Irrigation Department which was equal to $5.70 \mathrm{~mm} / \mathrm{d}$ or $2.08 \times 10^{7} \mathrm{~kg} /(\mathrm{ha} \cdot \mathrm{y})$; (3) average soil loss from crops in Thailand is $25 \mathrm{t} /$ (ha. $\mathrm{y}$ ) (Pansak, Hilger et al. 2008); (4) organic matter in soil is 1.5\% (Norsuwan, Marohn et al. 2014) with the energy content $14.6 \mathrm{GJ} / \mathrm{t}$ (Cohen, Brown et al. 2006); (5) replanting new crops required initial Napier stems about 3,100-3,800 kg ha; (6) initial Napier stems for cultivation were considered as an external input; (7) diesel fuel consumption rate for Napier grass growing and harvesting was estimated from data referred from (Morandi, Perrin et al. 2016); (8) for Napier grass transporting the truck capacity and distance from cultivation field to the plant were approximately 3 tons per trip and $56 \mathrm{~km}$ per trip, respectively. (9) data for all agricultural machinery was obtained from (Morandi, Perrin et al. 2016); (10) all machines for Napier grass cultivation were assumed to have 20 years lifetime; (11) the fresh biomass (initial moisture 30\%) was sun-dried before transporting to the biorefinery site (after sundried moisture 15\%); (12) Napier grass annual production rate (fresh Napier grass) is 70-80 $\mathrm{t}$ (ha.y), which was hence assumed to be $75 \mathrm{t}$ /(ha.y) (DEDE 2013); (13) the energy content of Napier grass is $18 \mathrm{MJ} / \mathrm{kg}$ (Flores, Urquiaga et al. 2012).

\subsubsection{Alternative scenarios for Napier grass crop production}

To improve the sustainability of Napier grass cultivation, the dependence on economic inputs could be reduced by promoting long term productivity with eco-efficient alternatives such as using biofuel driven machineries, and lower pollution levels on the farm (Maier, Szerencsits et al. 2016). This would provide the higher utilization of local resources and lower the dependence on external resources (De Jong, Van Ree et al. 2010). Non-renewable inputs, such as diesel, could be replaced by other fuels, or partially substituted by renewable inputs, to reduce the reliance on fossil fuels. Some might suggest to use machinery instead of human labor to reduce the labor emergy input. However, the use of machinery would need to take into account the indirect labor and fuel consumption. Thus, two scenarios were simulated to predict the possibility of those proposed suggestions; (1) use tractors for weed removal (higher machinery but lower direct labor input) and build the biorefinery plant close to the cultivation site (within $10 \mathrm{~km}$ distance); (2) extend scenario (1) by using biodiesel instead of conventional diesel. 


\subsection{Description of the biorefinery}

The biofuel production was developed using the Aspen Plus 8.6 simulation software. The main objective of this system is to reduce the dependence of imported inputs. Further, the chosen technologies were (1) potentially applicable and (2) using continuously regenerated raw materials.

The biorefinery model was simulated to provide 3 main purposes; 1 ) chemical production which were methanol and 2 grades of liquid fuels: the naphtha-range $\left(C_{5}-C_{12}\right)$ and diesel-range $\left(>C_{12}\right)$ qualities, 2$)$ a combined heat and power plant to generate utilities within the system and; 3 ) waste treating unit (syngas cleaning, $\mathrm{CO}_{2}$ capture and waste water treatment) to capture acid gas, treat and recycle water within the process. Also, the by-product from waste treating units were obtained including concentrated $\mathrm{CO}_{2}$ and sulfur cake. The details of the whole process were described as follow.

The first process in the biofuel production system was the gasification process, where the biomass is burnt with air and steam to produce syngas (Preciado, Ortiz-Martinez et al. 2012). The proposed reactor model in this process was the steam blown dual fluidized bed gasifier, since this is claimed to give a higher efficiency than a conventional gasifier (Doherty, Reynolds et al. 2013). The syngas outlet stream composed of steam, $\mathrm{H}_{2}, \mathrm{CO}, \mathrm{CO}_{2}$ and small amount of $\mathrm{H}_{2} \mathrm{~S}$. The hot $\left(1,300^{\circ} \mathrm{C}\right)$ gas produced in the gasifier was then sent through the CHP in the third process to extract the heat from the hot syngas stream. Also, the unconverted gas from further processes, such as HDP and methanol synthesis, was recovered back into the CHP where the gas and air combusted to provide more heat to the system. The steam that was generated, which carried a large amount of energy, was sent to the steam turbine to produce electricity. In this process, electricity and heat were produced simultaneously. Besides power, the $\mathrm{CHP}$ process produced steam under four conditions to support the whole system. These were medium temperature steam $\left(250{ }^{\circ} \mathrm{C}, 2.5 \mathrm{MPa}\right)$, high temperature steam $\left(500{ }^{\circ} \mathrm{C}, 2.5 \mathrm{MPa}\right)$, medium pressure steam $\left(200{ }^{\circ} \mathrm{C}, 2.8 \mathrm{MPa}\right)$ and high pressure steam $\left(510{ }^{\circ} \mathrm{C}, 6.2 \mathrm{MPa}\right)$. The heat and power generated were primarily used within the system, while the remaining were considered as external products including; $7.9 \mathrm{MW}$ electricity and $3.72 \times 10^{8} \mathrm{MJ}$ high pressure steam/y.

After the CHP process, the cold syngas stream $\left(180^{\circ} \mathrm{C}\right)$ went through the outlet to the gas cleaning process. In this process, the cold syngas was sent to the water scrubber to remove small particulates, such as fly ash, and was then delivered to the sour water-gas shift reactor to adjust the $\mathrm{CO}: \mathrm{H}_{2}$ ratio at 2.1. The sour gas was then sent to the monoethanolamine (MEA) absorber to remove the acid gases (including $\mathrm{CO}_{2}$ and $\mathrm{SO}_{2}$ ). The cleaned syngas was then fed into the fourth stage wherein the refined gas was synthesized to liquid fuels through the Fischer-Tropsch process. The reactor was operated at $200{ }^{\circ} \mathrm{C}$ and $2.5 \mathrm{MPa}$, based on the NREL literature model (Swanson, Platon et al. 2010). After the Fischer-Tropsch reaction, to obtain the liquid fuels with a high gasoline portion, the liquid product was treated with $\mathrm{H}_{2}$ in HDP. Finally, the liquid fuels within the naphtha-range $\left(\mathrm{C}_{5}-\mathrm{C}_{12}\right)$ and diesel-range $\left(>\mathrm{C}_{12}\right)$ qualities were obtained. The remaining unconverted syngas from the fuel synthesis was sent to the methanol synthesis process to produce methanol as a byproduct. The methanol synthesis was developed using kinetic reaction model referred from De María study (De María, Díaz et al. 2013). 
The assumptions for treatment of the wastes were based on the following literatures: (1) water condensate from the syngas production, which contained soluble volatile matter at less than $0.02 \%$ by mass and was treated and recycled to the CHP process for steam production. The emergy calculation data referred from Arbault (Arbault, Rugani et al. 2013). (2) the flue gas from the CHP process which contained $\mathrm{CO}_{2}$ at about 980 ppm was sent to the treating unit for carbon capture process where a high $\mathrm{CO}_{2}$ concentration was obtained as a by-product. The system referred from (Desideri and Antonelli 2014) where the amine absorption was employed. Also some economic information for emergy accounting referred from Singh (Singh, Croiset et al. 2003). No detailed simulation was made for the waste treatment processes.

\subsection{Equations and notations for emergy accounting}

The energy systems diagram of the system is shown in Fig. 1. To complete the emergy accounting, the amount of emergy input to the system was calculated by multiplying the raw data inputs (as mass flow, energy flow, etc.) with the emergy conversion factor (Unit Emergy Value; UEV), which was obtained from previous studies. The UEV indicates the amount of emergy required to produce a unit of product(s), expressed as sej/, sej $\mathrm{kg}$ or sej $\mathrm{L}$ of product. A higher UEV value means a larger amount of emergy input is required for the process to obtain the product(s). When comparing products or processes, the UEV can be used to reveal the resource use efficiency of the system, where the product with a lower UEV has a higher production efficiency (Bastianoni and Marchettini 1996).

Typically, the emergy input of the systems can be classified as free natural resources available within system boundary or economic inputs. Free natural resources are separated into renewable resources $(R)$ and non-renewable resources $(\mathrm{N}$ ). For example, renewable resources include solar radiation, wind and rain, while non-renewable resources include minerals and soil. Only the largest emergy flow among solar radiation, wind and rain is counted in order to avoid double counting of renewable resource (Odum 1996). Economic inputs can be classified into two types, i.e., purchased energy and materials ( $F$ ) and human labor (L). Labor may contribute directly (DL) or indirectly (IL) as services. An important emergy input to an agricultural production system is labor (labor directly applied to the process; DL) and services (external labor coming from the economic sector or larger scale outside the system boundary; IL). The economic inputs can be classified into renewable parts $\left(F_{R}+L_{R}\right)$ and non-renewable parts $\left(F_{N}+L_{N}\right)$ where $F=F_{N}+F_{R}$ and $L=L_{N}+L_{R}$. The emergy input from source $i$ is defined as $\mathrm{Em}_{\mathrm{i}}$ and the available energy of the product $\mathrm{j}$ is defined as $\mathrm{En}_{\mathrm{j}}$. In Eqs. (1) - (5), different emergy indicators are defined with respect to the four variables; R, N, F and L.The descriptions of each notation are summarized in Table 1.

$$
\begin{gathered}
\text { UEV of the product }(S), \tau=\frac{\sum_{i=1}^{n} E m_{i}}{\sum_{i=1}^{n} E n_{i}} \\
\text { Global Renewability, } \% R_{\text {global }}=\frac{R+F_{R}+L_{R}}{R+N+F+L} \\
\text { Environmental Loading Ratio, } E L R=\frac{N+F+L}{R} \\
\text { Emergy Yield Ratio, EYR }=\frac{R+N+F+L}{F+L}
\end{gathered}
$$


Emergy Sustainability Index, ESI $=\frac{E Y R}{E L R}$

The global renewability in equation $(2), \% R_{\text {global, }}$ is the indicator that is used to identify the fraction of resources used that comes from global renewable resources. While ELR, in equation (3), is the ratio of local non-renewable and economic inputs emergy to local renewable emergy, which implies the ecosystem stress due to the processes within the system boundary. The value reflects the renewable fraction of the system in a different way from $\% R_{\text {global. }}$. The ELR value indicates only the locally renewable resources that support the system while the $\% \mathrm{R}_{\text {global }}$ also counts the renewable fraction from economic inputs.

The emergy yield ratio (EYR), in equation (4), is the ratio of the total emergy that drives the system to the economic inputs emergy, and measures the ability of the system to exploit the local resources. The value should be much higher than 1 otherwise the process will act as a consumer rather than a producer. Finally, the ratio between ELR and EYR is presented as ESI in equation (5), the emergy sustainability indicator (ESI). In Eqs. (1) - (5), the sustainability in the ESI indicator was defined with respect to the four variables; R, N, F and L. The lowest possible value of ESI is zero. ESI value close to zero indicates the process produces negative yield to the society and creates large burden to environment. In the other hand, those greater than one indicates that the process has high contribution to the economy without creating heavily loads to its environment (Brown and Ulgiati 2004).

In this study, Napier plantation requires initial Napier stem to plant the crop that lasts for 7 years. Within this period of time, the UEV of output (Napier grass biomass) and input (initial Napier stem) were assumed to be equal. Iteration is often applied to deal with this issue (Morandi, Perrin et al. 2016), but the procedure employed in this study was derived from the mathematical formula described below studying equation (6).

Let $\tau_{\text {Napier }}$ be the UEV of the Napier grass biomass; $\mathrm{Em}_{0}, \mathrm{Em}_{\text {Napier,in }}$ and $\mathrm{Em}_{\text {Napier,out }}$ be the emergy flow of all inputs (except initial Napier stem), initial Napier stem and total emergy flow to the Napier grass biomass, respectively; and $M_{\text {Napier,in }}$ and $M_{\text {Napier,out }}$ be the amount of initial Napier stem and Napier grass biomass, respectively. The emergy accounted to the output will be equal to the summation of all the inputs including the initial Napier stem $\left(E m_{\text {Napier,out }}=E m_{0}+E m_{\text {Napier,in }}=E m_{0}+M_{\text {Napier,in }} \tau_{\text {Napier }}\right.$, while the total emergy to the output will equal the multiplication between the raw amount of product ( $\mathrm{M}_{\text {Napier,out }}$ ) and UEV of the product $\left(\tau_{\text {Napier). }}\right.$. Thus, equation (6) was obtained.

$$
\begin{aligned}
& E m_{\text {Napier,out }}=E m_{0}+M_{\text {Napier, in }} \tau_{\text {Napier }}=M_{\text {Napier,out }} \tau_{\text {Napier }} \\
& \text { Napier grass UEV, } \tau_{\text {Napier }}=\frac{E m_{0}}{\left(M_{\text {Napier,out }}-M_{\text {Napier, in })}\right)}
\end{aligned}
$$

\subsection{Emergy analysis of co-production process}

In emergy analysis, total emergy driving the process allocates to each of the products equally (Brown and Herendeen 1996). While this rule is applied, it is important to understand that one-product systems and multi-product systems cannot directly compare. When products cannot be produced independently in the 
process, the emergy allocated to each product from that process is equal to the total emergy inputs. According to the procedure, most multi-product systems often rely on higher emergy than one-product system. Since they carried the emergy of the whole production process. For example, the combine heat and power process which produces electricity and steam as by-product has UEV of $1.20 \times 10^{5} \mathrm{sej} / \mathrm{J}_{\text {electricity }}$ (Sha and Hurme 2012). While solar power generates the electricity with UEV only $8.92 \times 10^{4} \mathrm{sej} / \mathrm{J}_{\mathrm{electricity}}$ (Paoli, Vassallo et al. 2008). It may lead to misinterpretation if we compare the emergy of these products that were generated from these two processes.

Since the biorefinery system in this study has more than one product, joint and weighted average indicators were used (Bastianoni and Marchettini 2000). The joint production process is defined as the system that produces co-products simultaneously (Figure $2 \mathrm{a}$ ). The joint UEV $\left(\boldsymbol{\tau}_{\text {joint }}\right)$ was calculated by equation (7).

The weighted average indicators can be evaluated from the weighted emergy fraction by the energy contents of the products that have the same quantity as the joint-production products but produced by two or more independent ways (Figure $2 b$ ). The weighted average UEV ( $\tau_{\text {ave }}$ ) was evaluated using equation (8). The same procedure can be applied to other indicators, such as the EYR or ELR.

$$
\begin{gathered}
\text { Joint UEV, } \tau_{j o \text { int }}=\frac{E m_{b r f}}{E n_{m}+E n_{p}+E n_{s}+E n_{f}} \\
\text { Weighted average UEV, } \tau_{\text {avg }}=\frac{E n_{m}}{E n_{m}+E n_{p}+E n_{s}+E n_{f}} \tau_{m}+\frac{E n_{p}}{E n_{m}+E n_{p}+E n_{s}+E n_{f}} \tau_{p} \\
+\frac{E n_{s}}{E n_{m}+E n_{p}+E n_{s}+E n_{f}} \tau_{s}+\frac{E n_{f}}{E n_{m}+E n_{p}+E n_{s}+E n_{f}} \tau_{f}
\end{gathered}
$$

where $E n_{m}, E n_{p}, E n_{s}$ and $E n_{f}$ are the energy flow of methanol, electricity, steam and liquid fuels, respectively, from the biorefinery; $\tau_{m}, \tau_{p}, \tau_{s}$ and $\tau_{f}$ are the UEVs of methanol, electricity, steam and liquid fuels, respectively from independent production systems; $E_{\text {brf }}$ is the total emergy input to the biorefinery system; and $\mathrm{Em}_{\mathrm{m}}, \mathrm{Em}_{\mathrm{p}}, \mathrm{Em}_{\mathrm{s}}$ and $\mathrm{Em}_{\mathrm{f}}$ are the total emergy input to the methanol, electricity, steam and liquid fuels independent production system, respectively.

\subsection{Human labor in emergy accounting}

In emergy analysis, there are different procedures to include human resources into the emergy accounting. One of the conventional procedures is to use the emergy to money ratio (EMR) as the UEV for labor inputs in monetary units, where EMR is an indicator that expresses the quantity of emergy that supports the monetary value of the production or GDP of the country where the production takes place. It is measured in sej/US\$ or another relevant currency. For example, the global average EMR can be obtained by dividing the global emergy budget of $1.05 \times 10^{26} \mathrm{sej} / \mathrm{y}$ by the global money flow of $6.06 \times 10^{13}$ US\$ $\mathrm{y}$ (Kamp, Morandi et al. 2016) to give an UEV as emergy per monetary value of $1.73 \times 10^{12}$ sej/US\$.

Another approach for human labor accounting is to allocate the emergy budget per hour worked to each category using specific parameters. The refined method has been applied from that of (Kamp, Morandi et al. 
2016) considering the data for three production sectors in Thailand (agricultural, industry and services) for the year 2008 (Aemkulwat 2010). The assumption involved is using a money-based distribution to indicate the emergy shared to people working in different levels of the production process. In Thailand, the emergy budget of $3.20 \times 10^{24}$ sejy in 2008 was distributed across the labor system based on \%GDP distribution as follows; agriculture sector $8.8 \%\left(2.82 \times 10^{23} \mathrm{sej} / \mathrm{y}\right)$, industrial sector $48 \%\left(1.54 \times 10^{24} \mathrm{sej} / \mathrm{y}\right)$ and services $43.2 \%$ $\left(1.38 \times 10^{24} \operatorname{sej} y\right.$ ) (Aemkulwat 2010). The hours worked by each production sector were calculated using the average working hours and population of people working in each production sector, where the hours worked by people in the agricultural, industrial and service sectors were $3.11 \times 10^{10} \mathrm{~h} / \mathrm{y}, 1.71 \times 10^{10} \mathrm{~h} / \mathrm{y}$ and $3.29 \times 10^{10} \mathrm{~h} / \mathrm{y}$, respectively. The ratios between the emergy distribution and hours worked by each sector gave UEVs for people working in the agricultural, industrial and service sectors of $9.06 \times 10^{12} \mathrm{sej} / \mathrm{h}, 8.99 \times$ $10^{13} \mathrm{sej} / \mathrm{h}$ and $4.20 \times 10^{13} \mathrm{sej} / \mathrm{h}$, respectively, as fully described in the supplementary material (note 1.11 ).

Using EMR as human labor UEV or using man-hour UEV has distinct different advantages. The EMR is the expression of the average value of the whole nation, while the man-hour UEV is attempted to be the specific value of a sector sorted by level of income. In this study, both methods are applied. The direct labor input is considered a domestic labor, using man-hour UEV based on Thailand. Only the agricultural and industrial sectors were considered, since the labor involved farmers and industrial operators. For the indirect labor, which corresponded to external labor, the global average EMR was used as the labor UEV. The summary for labor UEV used in this study is shown in Table 2.

\section{Results and discussion}

Figure 1 depicts the process which is under investigation as described earlier. It is mainly composed of biomass cultivation section and biorefinery section. The details of emergy accounting for each section are tabulated in Table A1 - A8 as shown in the supplementary material. Also, the resource distributions to each production process is summarized in Table A9, where the emergy inputs to each process are categorized into $R, N, F$ and $L$ as mentioned in section 2.3.

\subsection{Emergy analysis of biomass cultivation}

The obtained emergy analysis of this study for Napier grass cultivation was compared with that previously reported in Table 3 to indicate the potential of Napier grass from Thailand as a lignocellulosic bioenergy crop. In addition to Napier grass, waste from palm oil production is also a potential bioenergy feedstock in Thailand. Comparison between Napier grass and palm cultivation revealed that the UEV of Napier grass was lower than that for palm oil which means that less resources are used to produce one joule of biomass. However, the global renewable fraction was lower which is not desirable. The major sources of emergy inputs to Napier cultivation were evapotranspiration which reflects the amount of water absorbed by Napier grass from natural resources followed by diesel consumption at 33\% and 30\% of the total emergy input, respectively. The direct on site labor had a high impact on the cultivation processes, due to it being rural farming. Since the direct labor is on-site labor, the UEV of Thailand was used to calculate the direct labor emergy input in this process. Since the renewability fraction in human resources in Thailand accounted for only $10 \%$, a high direct labor input to the Napier grass cultivation process caused a low renewability to the biomass product (NEAD, 2010). The present result showed that almost $60 \%$ of resources consumed were non-renewable, causing a high load to the environment, as presented in the emergy indicator values. However, the EYR for Napier grass cultivation was 1.53 (higher than 1), which means the process acts as a producer more than a consumer. Nevertheless, the EYR of Napier grass was still lower than 
miscanthus, switchgrass and sugarcane, since the process required much more imported and human resources as shown in Table 3. The ELR of Napier cultivation was 1.89, which lies within the moderate impact to the environment range, according to (Brown and Ulgiati 2004). Due to the lower renewability of the process, Napier grass cultivation generated the higher environmental load than miscanthus and sugarcane. Finally, the ESI of Napier grass cultivation, which indicated the sustainability of the process from the perspective of EYR and ELR, was one of the suitable candidate compared to the alternative biomasses reported in Table 3.

It is important to note that the input of labor may be calculated in different ways and includes more or less indirect labor. For comparison, when evaluated without labor $51 \%$ global renewability of Napier grass cultivation can be obtained with a lower ELR (1.00), a higher EYR (2.00) and ESI (2.00). However, comparison of the resource use for the cultivation of biomass by collating UEVs from different studies may be misleading due to the different assumptions and contexts of each study. For example, some literature values did not consider the indirect labor (Coppola, Bastianoni et al. 2009, Pereira and Ortega 2010, Morandi, Perrin et al. 2016), some did not take into account the renewability of the economic inputs (Lin and Sagisaka 2012) and some did not describe their assumptions relating to labor accounting, which was the main emergy input into their system (Goh and Lee 2010, Pereira and Ortega 2010). For those reasons, recalculation on the same basis is required as attempted in Table 3.

To improve the sustainability of Napier grass cultivation, two scenarios were simulated to predict the possibility of those proposed suggestions (described in Section 2.1.1). The results (Table 4) revealed an improved process in many aspects. For the first case, the UEV was reduced 1.45 -fold to $9.30 \times 10^{3} \mathrm{sej} / \mathrm{J}$, $\% \mathrm{R}_{\text {global }}$ increased 1.4 -fold to $55 \%$, EYR increased 1.31-fold to 2.01, ELR was reduced 1.91 -fold to 0.99 and the ESI was improved 1.95-fold to 2.04. In the second case, using biodiesel instead of conventional diesel fuel did not improve $\% R_{\text {global, }}$ since the biodiesel production process was highly dependent on external resources and most were non-renewable resources (17\%) (Nimmanterdwong, Chalermsinsuwan et al. 2015). For this reason, the ESI of this scenario in Table 4 also shows that, with current biodiesel production process, the substitution of diesel with biodiesel is not a good alternative (higher UEV but higher $\% \mathrm{R}_{\text {global). }}$ Thus, we propose model (1) over model (2), since it has a higher sustainability indicator and in addition, a lower UEV.

\subsection{Emergy analysis of the Napier-based biorefinery}

The Napier-based biorefinery system in this study was modeled based on technologies as previously mentioned that operated using material and energy carriers produced within the system as the first priority. In this way, we reduced the dependence of economic inputs and the system acted as partly self-sufficient.

The UEV of the biorefinery system was calculated as a joint UEV of four products, electricity, steam, liquid fuels (products from fuel synthesis process) and methanol, according to equation (7). The other products, such as ash, concentrated $\mathrm{CO}_{2}$ and sulfur cake, were considered as by-products and not taken into account since the references used to compare with our study might also have by-products that could not be directly compared with our case. Also, these by-products accounted for only small amount of the energy among all output products.

The heat and power generated from the biorefinery can reduce the amount of economic inputs by $3.45 \times$ $10^{10} \mathrm{~J} / \mathrm{y}$ (steam) and $8.40 \times 10^{9} \mathrm{~J} / \mathrm{y}$ (electricity), which accounted for $4.25 \times 10^{19} \mathrm{sej} / \mathrm{y}$ (assuming that steam and electricity were imported from a biomass CHP process outside the system boundary). In addition, the wastewater treatment unit provided recycled water to the system that could reduce the otherwise high 
amount of fresh water input to the system by almost $20 \mathrm{t} / \mathrm{h}$ accounting for $1.56 \times 10^{17} \mathrm{sej} / \mathrm{y}$. Therefore, by using the material and energy integration concept, a $27 \%$ lower emergy consumption was obtained.

An overview of the emergy profile (Figure 3 ) shows that the cultivation stage dominates the emergy consumption of the entire process, followed by the chemical production processes (including gasification, fuel synthesis, HDP and methanol synthesis), waste treatment units and CHP accounting for $44 \%, 30 \%, 23 \%$ and $3 \%$ of the total, respectively. The emergy allocated to each process is summarized in Figure 4 , where the highest resource consumption in the biorefinery was syngas cleaning and fuel synthesis (Table A9). The main input to fuel synthesis was purchased resources from cobalt catalyst ( $6 \%$ ). Makeup MEA, accounted for $14 \%$ of total emergy input to the biorefinery, fed to gas cleaning process to extract the low concentration of $\mathrm{CO}_{2}$ produced from gasification process.

From Table 5, the UEV for the biorefinery, which was considered as a joint production system (Figure 2a) was $3.31 \times 10^{4} \mathrm{sej} / \mathrm{J}$ and $1.96 \times 10^{4} \mathrm{sej} / J$ when including and not including the labor, respectively. The UEV indicates that about 33 thousand solar emergy was required to produce a joule of products from this biorefinery system. As the diversity of products created by the system has a different ability to do work, the joint UEV may not be an appropriate value to apply in further studies. On the other hand, it can be used to compare the biorefinery with single processes that produce an equal quantity and quality of the same products, as previously suggested (Bastianoni and Marchettini 2000). These authors defined a weighted average UEV (Equation (8)), where the UEV of the product is obtained from an independent process (Figure $2 b$ ).

A number of specific alternative ways to produce electricity, steam, liquid fuels and alcohol are presented in Table 6. Among the given options, the best route to produce the target products (the lowest weighted average UEV) is by producing methanol from willow, heat and power from biomass CHP, additional power from wind power (since the power to heat ratio of biomass CHP is insufficient) and bio-diesel from rapeseed. In the best scenario, the weighted average UEV is 2.9 times higher than the present study. Meaning that, the biorefinery has utilized, in emergy terms, the resources more efficiently than that of the existing independent production process.

The emergy indicators of the biorefinery, including global renewability, EYR, ELR and ESI, were calculated under the simulation information obtained from theoretical assumptions. Global renewability of the biorefinery system accounted for $23 \%$ of the total emergy input, which is quite low due to large fraction of non-renewable materials consumed by the agricultural process and most were consumed by the bio-based production system, such as makeup MEA for syngas cleaning and cobalt catalyst for fuel synthesis (data reported in Table A1-A7 supplementary material). While most resources consumed are external resources leading to lower EYR value (from 1.53 in cultivation phase to 1.21). Due to the low EYR from the upstream production system, an industrial system that always demands import resources as the main input would continuously lower the EYR value and increase the ELR value (accounted for $14 \%$ ) of the whole system since the import resources are considered as the parameter that caused the principal load to the environment. Finally, the obtained ESI of the Napier-based biorefinery was 0.25 . In addition, to achieve higher sustainability, the optimization of chemical consumption is required. From emergy analysis, we found that it is possible to obtain ESI up to 10 percent if 50 percent of MEA can be recovered in gas cleaning process.

\section{Conclusion and recommendations}


The emergy methodology for sustainability assessment has advantages in that it can reveal the importance of free environmental services and resources. In this study, emergy assessment was used as a tool for evaluating biorefinery based on biomass resources, and provided insight into the evaluated system in terms of environmental impacts and used resource efficiency in producing the outputs. The values will show whether the evaluated system is optimally employed. From the results, some limitations in emergy analysis was found. Due to globalization, societies utilize resources globally. For example, electricity might be imported from neighboring countries that is produced by wind or hydropower. According to the conventional definition of ESI, only the local renewable emergy is counted in the renewable fraction for calculating the sustainable index. Thus, to be more accurate, the global renewable resources should be recognized in the ESI. This would provide broader perspective to the sustainability of the processes which required a large portion of external inputs but were partially renewable.

The overall results revealed that the bio-based products are not a completely renewable. They depend mostly on non-renewable resources in both biomass cultivation and biorefinery stages. In the Napier grass cultivation process, the dominating emergy input is evapotranspiration, diesel consumption and human labor, respectively. Eventhough there was no agreement for human labor accounting methods, different assumptions among present emergy literatures have been made. Therefore, it is important to perform emergy evaluation either with or without human labor input to clarify the range of product UEV for the further studies.

The diesel fuel for biomass cultivation and transportation also dominated the ESI. Additionally, replacing this fossil fuel with alternative fuels cannot directly solve the problem. It would put our situation into a dilemma regarding the high indirect fossil fuel consumption behind the production process.

In most industrial production processes, all emergy inputs other than biomass are considered as external resources (except for some cases for example; geothermal power plant, wind power plant, etc.). Those are often produced from non-renewable resources, which made the system to have a low EYR and to create a high burden to the environment. Even our proposed biorefinery model, that attempts to promote the sustainability of the existing system, can achieve a higher efficiency in terms of resources utilization than the individual production systems currently in existence. Nonetheless, the ESI of the whole system is still too low and require further improvement. As suggested in the green engineering concept (Allenby and Richards 1994), besides maximize resource efficiency, renewable resources should replace non-renewable ones as much as possible.

\section{Acknowledgements}

The authors would like to thank the Department of Chemical Technology, Faculty of Science, Chulalongkorn University and Department of Chemical and Biochemical Engineering, Technical University of Denmark for all supports on this study. Also, this study was financially supported by the Thailand Research Fund (IRG5780001) and the Graduate School of Chulalongkorn University.

\section{References}

Aemkulwat, C., 2010. Labor force structure change and Thai labor market, 1990-2008, Proceedings of the Second Annual Conference of the Academic Network for Development in Asia (ANDA), pp. 1-19. 
Allenby, B.R., Richards, D.J., 1994. The greening of industrial ecosystems. National Academies Press.

Arbault, D., Rugani, B., Tiruta-Barna, L., Benetto, E., 2013. Emergy evaluation of water treatment processes. Ecological engineering 60, 172-182.

Bastianoni, S., Marchettini, N., 1996. Ethanol production from biomass: analysis of process efficiency and sustainability. Biomass and bioenergy 11, 411-418.

Bastianoni, S., Marchettini, N., 2000. The problem of co-production in environmental accounting by emergy analysis. Ecological Modelling 129, 187-193.

Brown, M.T., Herendeen, R.A., 1996. Embodied energy analysis and EMERGY analysis: a comparative view. Ecological Economics 19, 219-235.

Brown, M.T., Ulgiati, S., 2004. Emergy analysis and environmental accounting. Encyclopedia of energy 2, 329354.

Campbell, J.E., Lobell, D.B., Genova, R.C., Field, C.B., 2008. The global potential of bioenergy on abandoned agriculture lands. Environmental science \& technology 42, 5791-5794.

Cavalett, O., Ortega, E., 2010. Integrated environmental assessment of biodiesel production from soybean in Brazil. Journal of Cleaner Production 18, 55-70.

Chang, F.-C., Lin, L.-D., Ko, C.-H., Hsieh, H.-C., Yang, B.-Y., Chen, W.-H., Hwang, W.-S., 2017. Life cycle assessment of bioethanol production from three feedstocks and two fermentation waste reutilization schemes. Journal of Cleaner Production 143, 973-979.

Cohen, M.J., Brown, M.T., Shepherd, K.D., 2006. Estimating the environmental costs of soil erosion at multiple scales in Kenya using emergy synthesis. Agriculture, ecosystems \& environment 114, 249-269.

Coppola, F., Bastianoni, S., Østergård, H., 2009. Sustainability of bioethanol production from wheat with recycled residues as evaluated by Emergy assessment. Biomass and Bioenergy 33, 1626-1642.

De Jong, E., Van Ree, R., Sanders, J., Langeveld, J., 2010. Biorefineries: giving value to sustainable biomass use. The Biobased Economy: Biofuels, Materials and Chemicals in the Post-oil Era, 111-130.

De María, R., Díaz, I., Rodríguez, M., Sáiz, A., 2013. Industrial methanol from syngas: kinetic study and process simulation. Int J Chem React Eng 11, 469-477.

DEDE. 2010. การปลูกหญู้านเปียร์ปากช่อง 1. http://webkc.dede.go.th/webmax/sites/defaultffiles/คู่มือการปลูกหญู้านเปียร์.pdf [in Thai].

Desideri, U., Antonelli, M., 2014. A simplified method for the evaluation of the performance of coal fired power plant with carbon capture. Applied Thermal Engineering 64, 263-272.

Dincer, I., Rosen, M.A., 2012. Exergy: energy, environment and sustainable development. Newnes.

Doherty, W., Reynolds, A., Kennedy, D., 2013. Aspen plus simulation of biomass gasification in a steam blown dual fluidised bed.

Felix, E., Tilley, D.R., 2009. Integrated energy, environmental and financial analysis of ethanol production from cellulosic switchgrass. Energy 34, 410-436.

Flores, R.A., Urquiaga, S., Alves, B.J., Collier, L.S., Boddey, R.M., 2012. Yield and quality of elephant grass biomass produced in the cerrados region for bioenergy. Engenharia Agrícola 32, 831-839. 
Fontoura, C.F., Brandão, L.E., Gomes, L.L., 2015. Elephant grass biorefineries: towards a cleaner Brazilian energy matrix? Journal of Cleaner Production 96, 85-93.

Giampietro, M., Ulgiati, S., Pimentel, D., 1997. Feasibility of large-scale biofuel production. BioScience 47, 587-600.

Goh, C.S., Lee, K.T., 2010. Palm-based biofuel refinery (PBR) to substitute petroleum refinery: an energy and emergy assessment. Renewable and Sustainable Energy Reviews 14, 2986-2995.

Kamp, A., Morandi, F., Østergård, H., 2016. Development of concepts for human labour accounting in emergy assessment and other environmental sustainability assessment methods. Ecological Indicators 60, 884-892.

Lin, B.-L., Sagisaka, M., 2012. Sustainability assessment of bioethanol and petroleum fuel production in Japan based on emergy analysis. Energy policy 44, 23-33.

Maier, S., Szerencsits, M., Narodoslawsky, M., Ismail, I.M.I., Shahzad, K., 2016. Current potential of more sustainable biomass production using eco-efficient farming practices in Austria. Journal of Cleaner Production.

Morandi, F., Perrin, A., Østergård, H., 2016. Miscanthus as energy crop: Environmental assessment of a miscanthus biomass production case study in France. Journal of Cleaner Production 137, 313-321.

NEAD, 2010. The National Environmental Accounting Database (NEAD).

Nimmanterdwong, P., Chalermsinsuwan, B., Piumsomboon, P., 2015. Emergy evaluation of biofuels production in Thailand from different feedstocks. Ecological Engineering 74, 423-437.

Norsuwan, T., Marohn, C., Jintrawet, A., 2014. Effects of irrigation treatments and nitrogen applications on Napier grass planted in dry season as energy crop at Chiang Mai province.

Odum, H.T., 1996. Environmental accounting. Wiley,

Owens, J., 1997. Life $\square$ cycle assessment: Constraints on moving from inventory to impact assessment. Journal of industrial ecology 1, 37-49.

Pansak, W., Hilger, T., Dercon, G., Kongkaew, T., Cadisch, G., 2008. Changes in the relationship between soil erosion and $\mathrm{N}$ loss pathways after establishing soil conservation systems in uplands of Northeast Thailand. Agriculture, Ecosystems \& Environment 128, 167-176.

Paoli, C., Vassallo, P., Fabiano, M., 2008. Solar power: an approach to transformity evaluation. Ecological engineering 34, 191-206.

Patrizi, N., Pulselli, F.M., Morandi, F., Bastianoni, S., 2015. Evaluation of the emergy investment needed for bioethanol production in a biorefinery using residual resources and energy. Journal of Cleaner Production 96, 549-556.

Pereira, C.L., Ortega, E., 2010. Sustainability assessment of large-scale ethanol production from sugarcane. Journal of Cleaner Production 18, 77-82.

Preciado, J.E., Ortiz-Martinez, J.J., Gonzalez-Rivera, J.C., Sierra-Ramirez, R., Gordillo, G., 2012. Simulation of Synthesis Gas Production from Steam Oxygen Gasification of Colombian Coal Using Aspen Plus ${ }^{\circledR}$. Energies 5, 4924-4940. 
Sengupta, D., Pike, R.W., 2012. Chemicals from biomass: integrating bioprocesses into chemical production complexes for sustainable development. CRC Press.

Sha, S., Hurme, M., 2012. Emergy evaluation of combined heat and power plant processes. Applied Thermal Engineering 43, 67-74.

Singh, D., Croiset, E., Douglas, P.L., Douglas, M.A., 2003. Techno-economic study of CO2 capture from an existing coal-fired power plant: MEA scrubbing vs. $02 / \mathrm{CO} 2$ recycle combustion. Energy conversion and Management 44, 3073-3091.

Swanson, R.M., Platon, A., Satrio, J.A., Brown, R.C., 2010. Techno-economic analysis of biomass-to-liquids production based on gasification. Fuel 89, S11-S19.

Tilman, D., Socolow, R., Foley, J.A., Hill, J., Larson, E., Lynd, L., Pacala, S., Reilly, J., Searchinger, T., Somerville, C., 2009. Beneficial biofuels_the food, energy, and environment trilemma. Science 325, 270-271.

TMD, 2016. Thai Meteorological Department.

UND, 2011. International heat flow database.

\section{Figure captions}

Fig. 1 Flow diagram of the system including biomass cultivation and biorefinery.

Fig. 2 Alternative pathways to produce the target products. (a) The joint production system and (b) the alternative independent production system.

Fig. 3 Emergy profile for the system including biomass cultivation and biorefinery.

Fig. 4 Emergy profile for each process from field to biorefinery plant gate.

\section{Tables}

Table 1 Description of abbreviations and notations used in equations.

Table 2 The human labor UEVs used in this study.

Table 3 Emergy assessment of cultivation of different lignocellulosic biomass as feedstock.

Table 4 Two alternative models for improving Napier grass cultivation in Thailand.

Table 5 Emergy indicators of the system from cultivation to biorefinery.

Table 6 Alternative pathways to produce the target products.

Table A1 Emergy analysis of napier grass plantation.

Table A2 Emergy analysis of biomass gasification process.

Table A3 Emergy analysis of CHP process.

Table A4 Emergy analysis of syngas cleaning process

Table A5 Emergy analysis of fuel synthesis process.

Table A6 Emergy analysis of hydroprocessing.

Table A7 Emergy analysis of methanol synthesis process.

Table A8 Emergy analysis of waste treating process.

Table A9 Resources distributions to each production process. 
Table A10 Lists of UEVs used in this study (the values are based on the $1.20 \times 1025$ sej/y baseline (Brown, Protano et al. 2011)). 


\begin{tabular}{|c|c|}
\hline $\begin{array}{l}\text { Abbreviations/ } \\
\text { Notations }\end{array}$ & Descriptions \\
\hline UEV & Unit emergy value \\
\hline sej & Solar equivalent joule \\
\hline LCA & Life cycle analysis \\
\hline $\mathrm{CHP}$ & Combined heat and power plant \\
\hline HDP & Hydroprocessing \\
\hline $\begin{array}{l}\text { EMR } \\
\text { equation (1) }\end{array}$ & Emergy to money ratio \\
\hline $\mathrm{Em}_{\mathrm{i}}$ & Emergy of source $\mathrm{i}(\mathrm{sej} / \mathrm{y})$ \\
\hline$E n_{j}$ & Energy flow of product $\mathrm{j}(\mathrm{J} / \mathrm{y})$ \\
\hline$\tau$ & Unit emergy value (sej/J) \\
\hline \multicolumn{2}{|c|}{ equations (2) - (5) } \\
\hline$\% \mathrm{R}_{\text {global }}$ & Global renewability \\
\hline ELR & Environmental loading ratio \\
\hline EYR & Emergy yield ratio \\
\hline ESI & Emergy sustainability index \\
\hline $\mathrm{R}$ & Free natural resources as renewable resources \\
\hline$F_{R}$ & Renewable portion of purchased energy and materials (excluded human labor) \\
\hline$L_{R}$ & Renewable portion of human labor \\
\hline N & Free natural resources as non-renewable resources \\
\hline $\mathrm{F}$ & Purchased energy and materials (excluded human labor) \\
\hline L & Human labor \\
\hline \multicolumn{2}{|l|}{ equations (6) } \\
\hline $\mathrm{Em}_{\text {Napier,out }}$ & Total emergy flow to the Napier grass biomass \\
\hline $\mathrm{Em}_{0}$ & Emergy flow of all inputs (except initial Napier stem) \\
\hline Em $m_{\text {Napier,in }}$ & Emergy flow of initial Napier stem \\
\hline$M_{\text {Napier,in }}$ & The amount of initial Napier stem as input stream \\
\hline$M_{\text {Napier,out }}$ & The amount of initial Napier grass biomass as product stream \\
\hline$\tau_{\text {Napier }}$ & Unit emergy value of Napier grass (sej/J) \\
\hline \multicolumn{2}{|c|}{ equations (7) and ( 8 ) } \\
\hline$\tau_{\text {joint }}$ & Unit emergy value of the products from joint production system (sej/) \\
\hline $\mathrm{Em}_{\text {brf }}$ & Total emergy flow to the biorefinery (sej/y) \\
\hline $\mathrm{En}_{\mathrm{m}}$ & Energy flow of methanol product $(\mathrm{J} / \mathrm{y})$ \\
\hline $\mathrm{En}_{\mathrm{p}}$ & Energy flow of electricity generated $(\mathrm{J} / \mathrm{y})$ \\
\hline $\mathrm{En}_{\mathrm{s}}$ & Energy flow of steam product $(\mathrm{J} / \mathrm{y})$ \\
\hline $\mathrm{En}_{\mathrm{f}}$ & Energy flow of liquid fuels product $(\mathrm{J} / \mathrm{y})$ \\
\hline$\tau_{\text {avg }}$ & Unit emergy value of the products from independent production system (sej/) \\
\hline$\tau_{\mathrm{m}}$ & Unit emergy value of methanol produced independently (sej/) \\
\hline$\tau_{\mathrm{p}}$ & Unit emergy value of electricity produced independently (sej/) \\
\hline$\tau_{s}$ & Unit emergy value of steam produced independently (sej/J) \\
\hline$\tau_{f}$ & Unit emergy value of liquid fuels produced independently (sej/J) \\
\hline
\end{tabular}


Table 2 The human labor UEVs used in this study. D MANUSCRIPT

\begin{tabular}{|c|c|c|c|c|}
\hline & Level & UEV & Unit & Supplementary material \\
\hline \multirow{2}{*}{ Direct labor (DL) } & Agricultural sector & $9.06 \times 10^{12}$ & sej/h & \multirow{2}{*}{ Note 1.11} \\
\hline & Industrial sector & $8.99 \times 10^{13}$ & sej/h & \\
\hline Indirect labor (IL) & Global average & $1.73 \times 10^{12}$ & sej/\$ & Note 1.12 \\
\hline
\end{tabular}


Table 3 Emergy assessment of cultivation of different lignocellulosic biomass as feedstock.

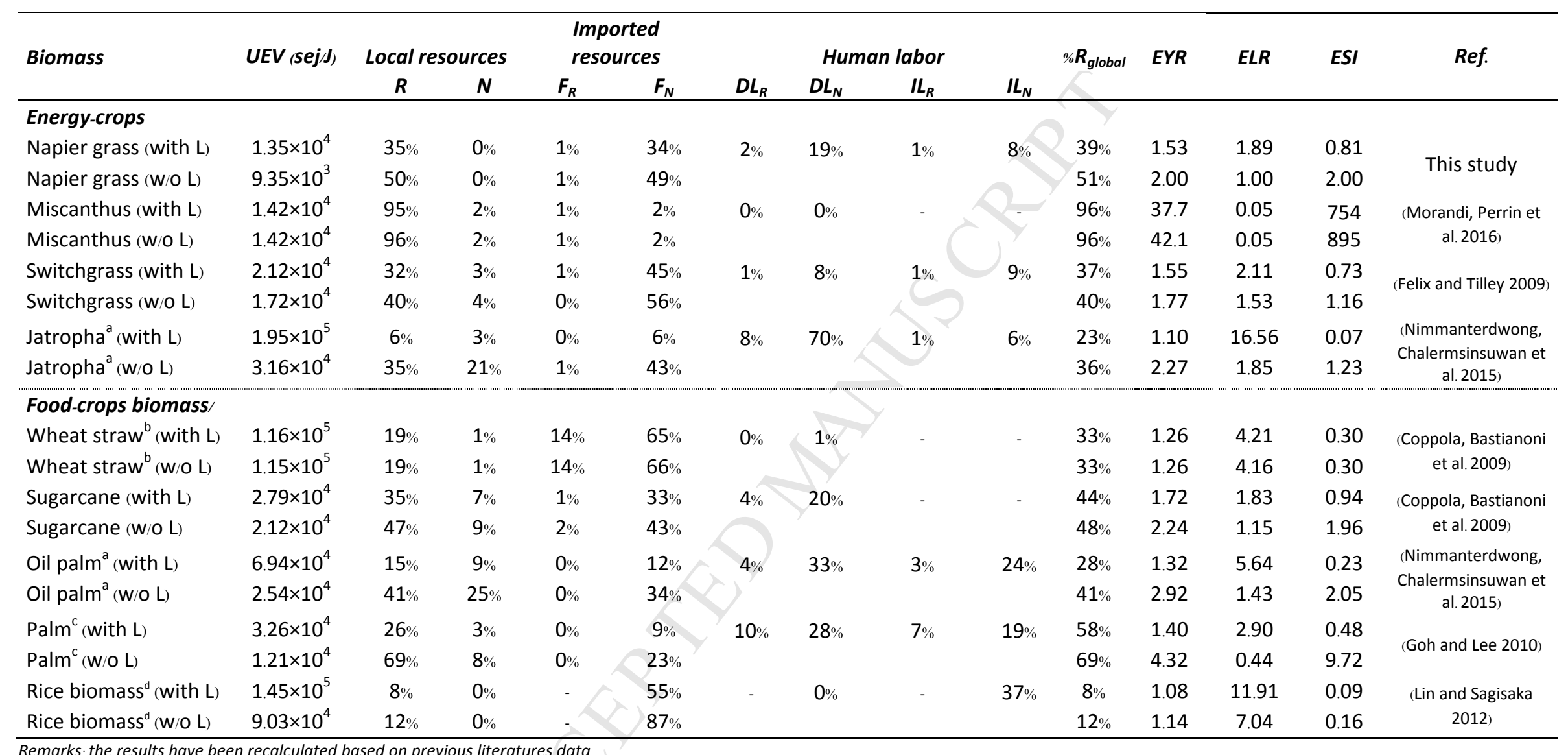

Remarks: the results have been recalculated based on previous literatures data.

- These missing numbers could not track from the reference literatures.

a Jatropha and oil palm production in Thailand, with extracted oil and produced residues as a by-product.

${ }^{\mathrm{b}}$ Case LO (organic management in loamy soil) was selected.

${ }^{c}$ Palm production in Malaysia, with extracted oil and produced residues as a by-product.

${ }^{d}$ Rice biomass includes rice grain, rice straw and chaff. 
Table 4 Two alternative models for improving Napier grass cultivation in Thailand.

\begin{tabular}{lccc}
\hline & Base case & $\begin{array}{c}\text { Proposed } \\
\text { model 1* }\end{array}$ & $\begin{array}{c}\text { Proposed } \\
\text { model 2** }\end{array}$ \\
\hline Total emergy flow $(\mathrm{sej} / \mathrm{y})$ & $6.39 \times 10^{19}$ & $4.40 \times 10^{19}$ & $4.81 \times 10^{19}$ \\
$\quad$ Local resources $(\mathrm{R}+\mathrm{N}), \%$ from total & $35 \%$ & $50 \%$ & $46 \%$ \\
Resources from outside $(\mathrm{F}), \%$ from total & $35 \%$ & $25 \%$ & $31 \%$ \\
Labor (direct \& indirect), \% from total & $31 \%$ & $25 \%$ & $23 \%$ \\
\hline $\mathrm{UEV}(\mathrm{sej} / \mathrm{J})$ & $1.35 \times 10^{4}$ & $9.30 \times 10^{3}$ & $1.02 \times 10^{4}$ \\
$\% \mathrm{R}_{\mathrm{global}}$ & $39 \%$ & $55 \%$ & $55 \%$ \\
$\mathrm{EYR}=(\mathrm{R}+\mathrm{N}+\mathrm{F}+\mathrm{L}) /(\mathrm{F}+\mathrm{L})$ & 1.53 & 2.01 & 1.86 \\
$\mathrm{ELR}=(\mathrm{N}+\mathrm{F}+\mathrm{L}) / \mathrm{R}$ & 1.89 & 0.99 & 1.17 \\
$\mathrm{ESI}=\mathrm{EYR} / \mathrm{ELR}$ & 0.81 & 2.04 & 1.58 \\
\hline
\end{tabular}

* Using tractors for weed removal, build biorefinery plant close $(<10 \mathrm{~km})$ to the cultivation site

** Using biodiesel instead of diesel, tractors for weed removal, build biorefinery plant close $(<10 \mathrm{~km})$ to the cultivation site

Table 5 Emergy indicators of the system from cultivation to biorefinery.

\begin{tabular}{lcc}
\hline Item & & Unit \\
\hline Joint UEV of the products with $\mathrm{L}$ & $3.31 \times 10^{4}$ & $\mathrm{sej} / \mathrm{J}$ \\
Joint UEV of the products without $\mathrm{L}$ & $1.96 \times 10^{4}$ & $\mathrm{sej} / \mathrm{J}$ \\
Global Renewability $\left(\% \mathrm{R}_{\text {global }}\right)$ & $23 \%$ & \\
EYR of the system $=(\mathrm{R}+\mathrm{N}+\mathrm{F}+\mathrm{L}) /(\mathrm{F}+\mathrm{L})$ & 1.21 & \\
ELR of the system $=(\mathrm{N}+\mathrm{F}+\mathrm{L}) / \mathrm{R}$ & 4.88 & \\
ESI of the system $=\mathrm{EYR} / \mathrm{ELR}$ & $\mathbf{0 . 2 5}$ & \\
\hline
\end{tabular}


Table 6 Alternative pathways to produce the target products.

\begin{tabular}{|c|c|c|c|}
\hline & $\begin{array}{l}\text { Country } \\
\text { source }\end{array}$ & UEV (sej/) & Ref. \\
\hline \multicolumn{4}{|l|}{ Bio-alcohol } \\
\hline Methanol from willow & Sweden & $6.06 \times 10^{4}$ & (Cavalett and Rydberg 2011) \\
\hline Methanol from wood & Italy & $2.66 \times 10^{5}$ & (Pimentel and Patzek 2008) \\
\hline \multicolumn{4}{|c|}{ Steam and power co-production } \\
\hline Biomass CHP process 1 & Finland & $1.62 \times 10^{4}$ & (Sha, Losowska et al. 2011) \\
\hline Biomass CHP process 2 & Finland & $3.44 \times 10^{4}$ & (Sha and Hurme 2012) \\
\hline Biomass CHP process 3 & Denmark & $2.31 \times 10^{5}$ & (Kamp and Østergård 2013) \\
\hline \multicolumn{4}{|l|}{ Power } \\
\hline Wood power plant & USA & $6.72 \times 10^{4}$ & (Odum 1996) \\
\hline CSP powerplant & China & $6.39 \times 10^{4}$ & (Zhang, Wang et al. 2012) \\
\hline Solar power plant & Italy & $8.92 \times 10^{4}$ & (Paoli, Vassallo et al. 2008) \\
\hline Wind power 1 & China & $1.74 \times 10^{4}$ & (Yang, Chen et al. 2013) \\
\hline Wind power 2 & Italy & $6.21 \times 10^{4}$ & (Brown and Ulgiati 2002) \\
\hline Geothermal power plant & Italy & $1.47 \times 10^{5}$ & (Brown and Ulgiati 2002) \\
\hline Hydro power plant 1 & Italy & $6.23 \times 10^{4}$ & (Brown and Ulgiati 2002) \\
\hline Hydro power plant 2 & Tibet & $1.56 \times 10^{5}$ & (Zhang, Pang et al. 2016) \\
\hline Hydro power plant 3 & Brazil & $8.28 \times 10^{4}$ & (Tassinari, Bonilla et al. 2016) \\
\hline \multicolumn{4}{|l|}{ Liquid fuels } \\
\hline Macroalgae oil 1 & Italy & $2.64 \times 10^{7}$ & (Bastianoni, Coppola et al. 2008) \\
\hline Macroalgae oil 2 & Brazil & $3.51 \times 10^{5}$ & (da Cruz and do Nascimento 2012) \\
\hline Bio-diesel from soy bean & Brazil & $3.90 \times 10^{5}$ & (Cavalett and Ortega 2010) \\
\hline Bio-diesel from palm oil & Thailand & $2.14 \times 10^{5}$ & $\begin{array}{l}\text { (Nimmanterdwong, } \\
\text { Chalermsinsuwan et al. 2015) }\end{array}$ \\
\hline $\begin{array}{l}\text { Weighted average UEV } \\
\text { best scenario* }\end{array}$ & & $9.57 \times 10^{4}$ & \\
\hline
\end{tabular}

*Methanol from willow, heat and power from biomass CHP process 1, additional power from Chinese wind power and bio-diesel from palm oil

CSP $=$ concentrating solar power 


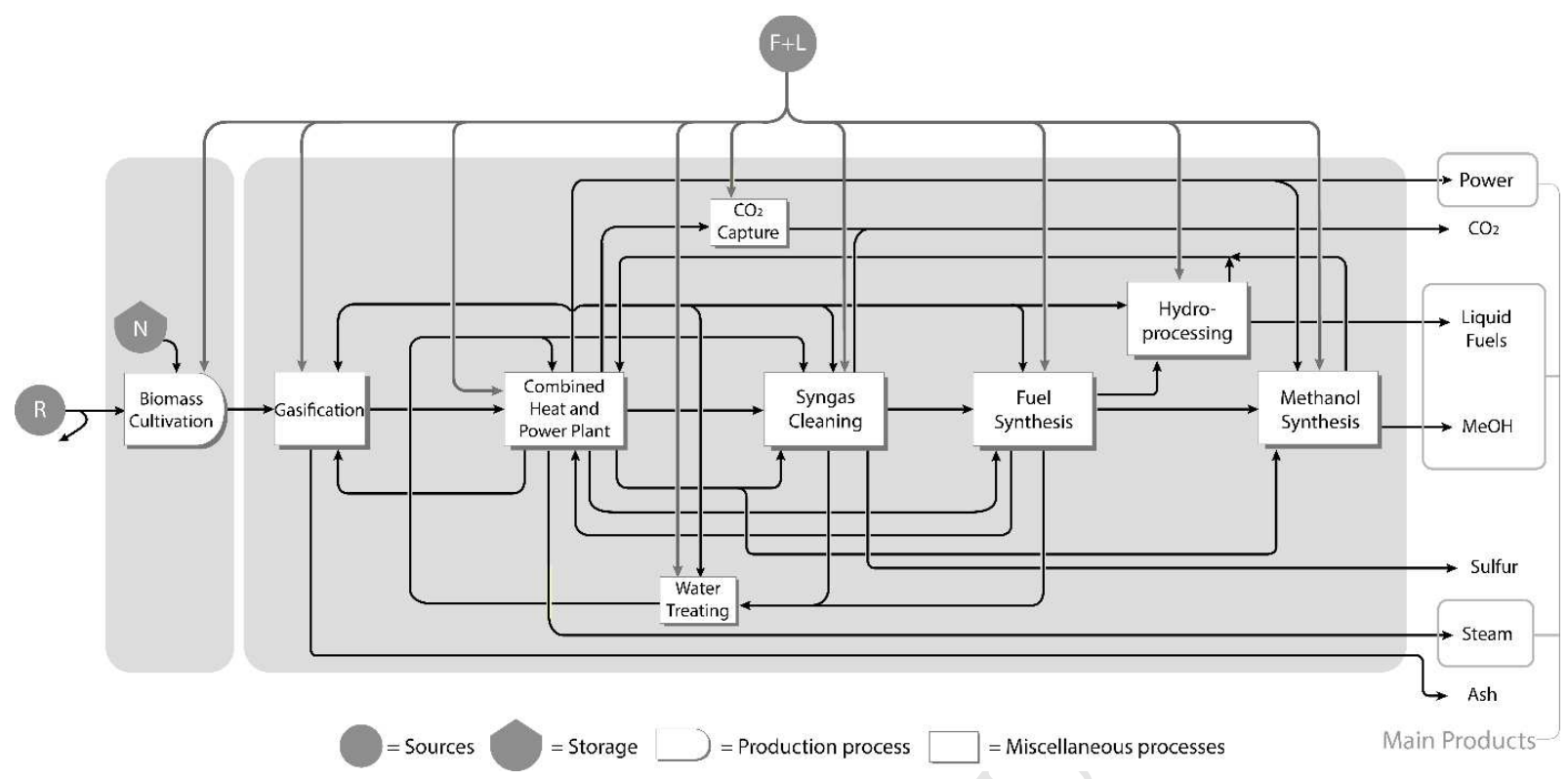

Fig. 1 Flow diagram of the system including biomass cultivation and biorefinery. 
a)

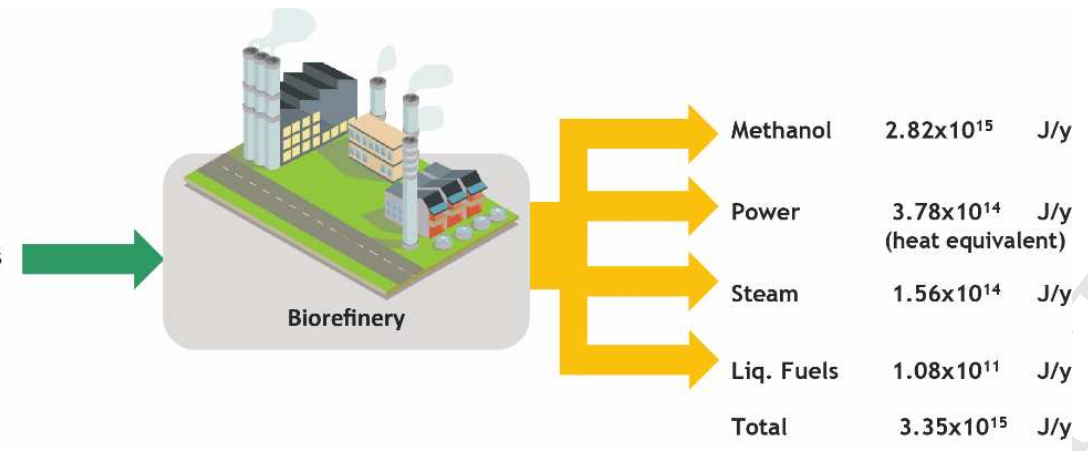

b)

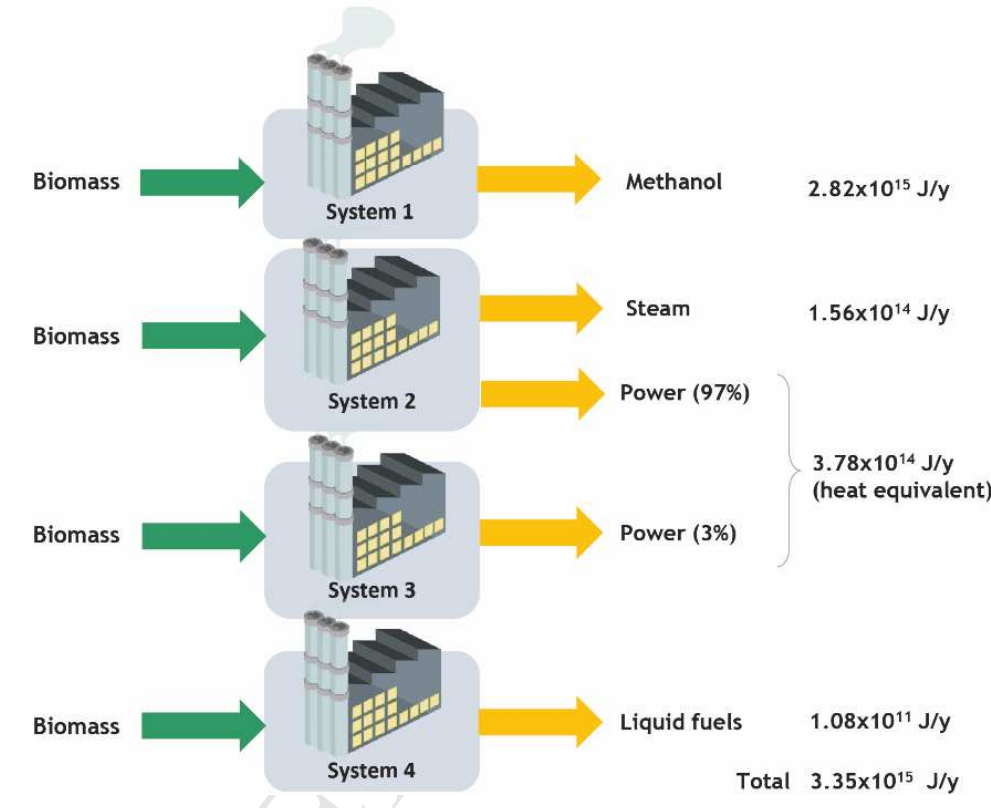

Fig. 2 Alternative pathways to produce the target products: (a) the joint production system and (b) the alternative independent production system. 


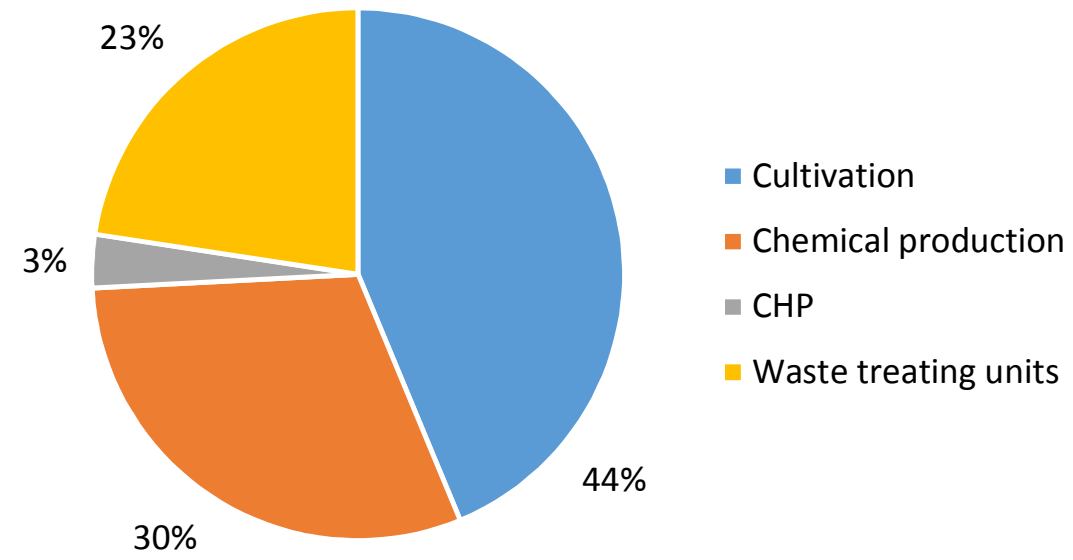

Fig. 3 Emergy profile for the system including biomass cultivation and biorefinery. 


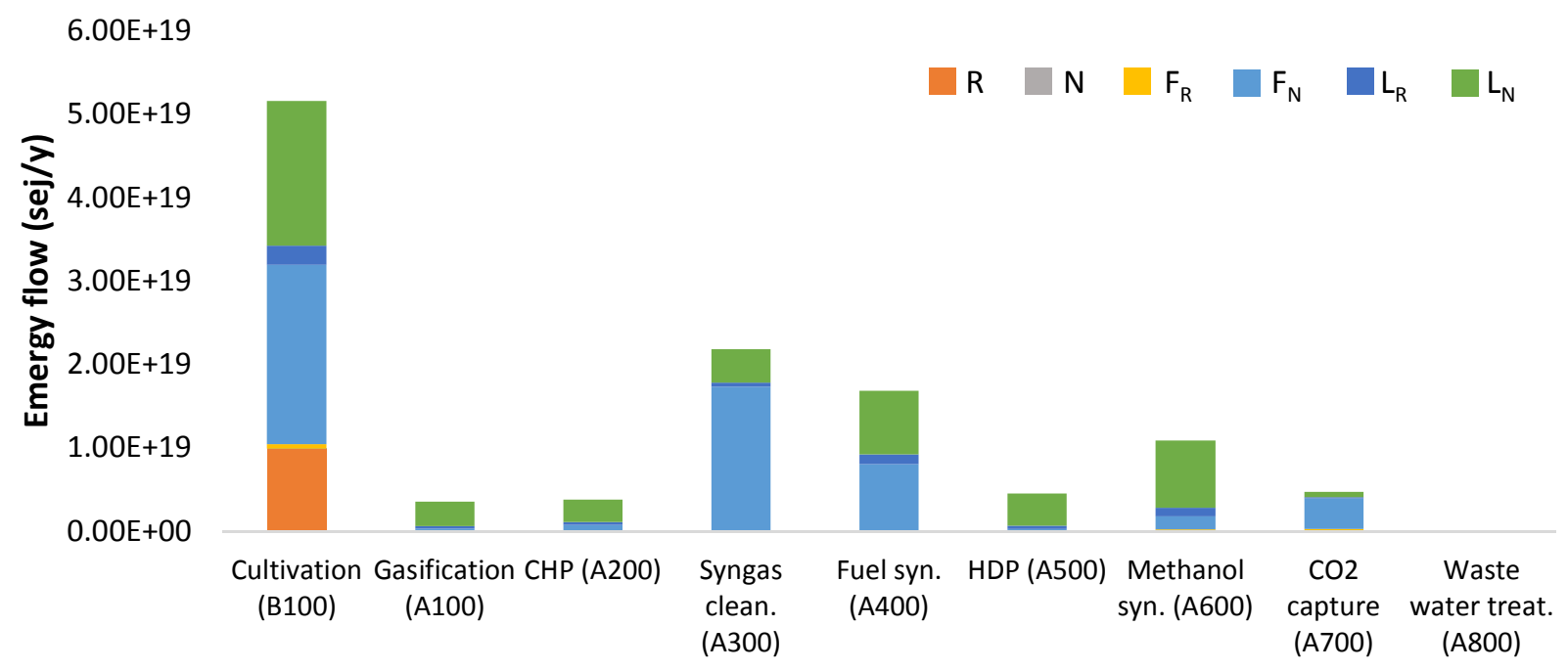

Fig. 4 Emergy profile for each process from field to biorefinery plant gate. 


\section{Environmental Performance Assessment of Napier Grass for Bioenergy Production}

\section{Prathana Nimmanterdwong ${ }^{\mathrm{a}}$, Benjapon Chalermsinsuwan ${ }^{\mathrm{a}, \mathrm{b}}$, , Hanne $\emptyset_{\text {stergård }}{ }^{c}$, Pornpote Piumsomboon ${ }^{\mathrm{a}, \mathrm{b}, *}$}

${ }^{a}$ Fuels Research Center, Department of Chemical Technology, Faculty of Science, Chulalongkorn University, 254 Phayathai Road, Pathumwan, Bangkok 10330, Thailand

${ }^{\mathrm{b}}$ Center of Excellence on Petrochemical and Materials Technology, Chulalongkorn University, 254 Phayathai Road, Pathumwan, Bangkok 10330, Thailand

${ }^{c}$ Department of Chemical and Biochemical Engineering, Technical University of Denmark, DTU, Søltofts Plads 229, 2800 Kgs. Lyngby, Denmark

\section{Highlights}

- Emergy analysis is employed to biomass cultivation and biorefinery processes.

- Heavy consumption of non-renewable resources in Napier grass cultivation was found.

- The proposed biorefinery can achieve a higher emergy performance than existing ones.

- The proposed biorefinery consists of material and energy through reuse and recycling.

- Human labor and renewable resource accounting was discussed. 